\title{
Food Policy Council Case Study Describing Cross-sector Collaboration for Food System Change in a Rural Setting
}

\author{
Larissa Calancie, $\mathrm{PhD}^{1}$, Nathanial Stritzinger, $\mathrm{MPH}^{2}$, Jaclyn Konich, $\mathrm{RD}, \mathrm{MPH}^{2}$, Camille Horton, $\mathrm{MPH}^{2}$, Nicole E. Allen, $\mathrm{PhD}^{3}$, Shu Wen Ng, $\mathrm{PhD}{ }^{2,4}$, \\ Bryan J. Weiner, PhD 5 , Alice S. Ammerman, DrPH ${ }^{2,6}$ \\ (1) Center for Health Equity Research, Department of Social Medicine, School of Medicine, University of North Carolina at Chapel Hill; (2) Department of Nutrition, Gillings \\ School of Global Public Health, University of North Carolina at Chapel Hill; (3) Department of Psychology, University of Illinois at Urbana-Champaign; (4) Carolina Population \\ Center, University of North Carolina at Chapel Hill; (5) Department of Health Services, University of Washington; (6) Center for Health Promotion and Disease Prevention, \\ University of North Carolina at Chapel Hill
}

Submitted 29 August 2016, revised 07 April 2017, accepted 23 April 2017.

\section{Abstract}

Problem: Food Policy Councils (FPCs) are cross-sector collaborations that bring representatives from across the food system together to identify issues, coordinate programs, and inform policy. Little is known about how rural FPCs operate to influence food access in their communities.

Purpose: To explore how a rural FPC facilitates cross-sector partnerships and influences food system change through interviews with eight members of the Adam's County FPC.

Results: Connections developed through the FPC helped council members work more effectively in their home organizations. Four themes were discussed: council dynamics and structure; sharing resources, expertise, and information;

1 There is typically no "Department of Food" in communities; consequently, disparate departments and organizations address food issues, often in isolation. ${ }^{1}$ For example, agriculture departments may oversee food production and distribution while health departments influence food consumption through food safety regulations. Serving as an arena for collaboration across sectors and community groups, Food Policy Councils (FPCs) can change the way food is produced, distributed, accessed, consumed, and disposed of within a community. ${ }^{2}$ FPCs are organizations that bring together representatives from across the food system to efficiently identify issues, coordinate programs, and influence policy. ${ }^{3}$ There are 278 FPCs in the United States, Canada, and Tribal Nations listed in the promoting healthy food access through programs; and food policy opportunities and challenges.

Conclusions: This case study illustrates connections between FPC members in a rural county and identifies how FPCs can facilitate food system change in their communities. Improving our understanding of how rural FPCs function can help to advance the potential public health impact of councils.

\section{Keywords}

nutrition, community health partnerships, health promotion, process issues, rural health, agriculture

2015 Food Policy Network's FPC Directory. ${ }^{4}$ Given the strong links between food systems, access to healthy foods, diet, and health, ${ }^{5,6}$ FPCs' activities have the potential to improve health outcomes in communities across the country. Partnerships are central to the work of FPCs. ${ }^{7}$ FPC members build partnerships across sectors to influence food policy, gain input from stakeholders, set policy agendas, and develop legitimacy. ${ }^{7}$

Most peer-reviewed FPC literature focuses on urban FPCs, often describing the role of an FPC in policy changes related to urban agriculture ${ }^{8-10}$ or urban food systems. ${ }^{11,12}$ Other studies synthesize findings across FPCs and do not indicate whether the included councils operate in rural or urban settings. ${ }^{2,13}$ One recent case study exploring an Australian food policy 
coalition in a rural setting found that, with strong leadership, the group could positively influence the local food environment. ${ }^{14}$ Specifically, the coalition's advocacy work led to policy changes allowing produce gardens on public land. ${ }^{14}$ We found no peer-reviewed literature expressly investigating how FPCs function in rural settings in the United States.

Rural settings may differ from urban and suburban settings in terms of available resources, economic role of agriculture, access to food outlets, and health outcomes. ${ }^{15,16}$ Obesity, nutrition-related chronic disease, and hunger are often higher in areas with low population density, compared with urban and suburban populations. ${ }^{17,18}$ The purpose of this case study is to explore how an FPC in a rural community facilitates collaboration and partnerships across sectors, what activities their members do to further their councils' mission, and their members' perceptions about food policy.

\section{METHODS}

We conducted interviews to gain an in-depth perspective of the Adams County Food Policy Council (ACFPC). The ACFPC was selected for this case study at the recommendation of a member of the Nutrition and Obesity Policy Research and Evaluation Network FPC working group, who was familiar with the council, but was not a member. ${ }^{19}$ Adams County, a rural county in southern Pennsylvania, served as the case study setting. The county's population was approximately 101,482 in 2012; about $91 \%$ of residents were White, $2 \%$ Black, $6 \%$ Hispanic, and $1 \%$ identify as another race. ${ }^{20}$ One-half of the land in the county was devoted to agriculture and the median household income was $\$ 60,356 .{ }^{20}$ An estimated 9.5\% of the population was food insecure. ${ }^{21}$ The Adams County Commissioners officially established the ACFPC in 2009 through a county proclamation. ${ }^{22}$ Once established, the council developed the following mission statement: "In the interest of health and sustainability, the ACFPC promotes the integration of the individual, community, the economy, and the environment. We engage with businesses, institutions, social service agencies, community members, the agricultural sector, and government to develop food policy and take action." ${ }^{22}$ A paid AmeriCORPS Vista member facilitates meetings, organizes the council's records, and works with partner organizations. The council's 13 active members meet in person monthly. The council does not have working groups or a formal leader.

\section{Data Collection Procedures}

The research team used the Community Coalition Action Theory and literature about community collaboratives, ${ }^{23-26}$ and literature about FPCs to develop an interview guide to elicit perceptions about the ACFPC from council members. ${ }^{2,3,7,13}$ Questions on the interview guide prompted participants to describe their councils' group dynamics, relationships with other council members and partners, and activities they undertook to help their council achieve its mission. Interviewers also asked participants about how they define food policy and opportunities they saw for food policy in their county. A former coordinator for the ACFPC and an expert on organizational research reviewed the interview guide. The guide was revised based on their feedback.

The current ACFPC coordinator assisted in recruiting the interview participants. The coordinator forwarded the 13 active council members a recruitment email that introduced the study and asked interested members to contact the research team to schedule an interview. Phone interviews took place in November of 2014. They lasted 20 to 50 minutes, and were recorded and transcribed verbatim. Two members of the research team who were not associated with the ACFPC conducted the interviews. The University of North Carolina at Chapel Hill Institutional Review Board reviewed and approved this study, and all participants gave permission to have their de-identified transcripts read by the research team. The participants were informed that the research team included a former ACFPC coordinator.

\section{Qualitative Analysis}

The primary author developed an initial codebook deductively by using constructs from community collaboration literature ${ }^{23-26}$ and inductively by reading interview transcripts. ${ }^{27}$ The primary author selected two interview transcripts that all members of the data collection team read and coded using the codebook. The team met to compare their coded transcript, and then revise the codebook, adding new codes and removing irrelevant codes. Next, the primary author and another team member coded each transcript using the revised codebook, and then the coders met to reconcile their codes and develop a consensus. Data were reduced into a matrix and condensed into four themes using Dedoose..$^{27,28}$ 


\section{RESULTS}

All 13 active council members were sent a recruitment email and 8 elected to participate in interviews. At the time of participant recruitment, all active ACFPC members were female. Table 1 shows the sectors where study participants work. Findings from the codes were synthesized into the following four themes that represent how the ACFPC facilitates cross-sector collaboration and influences their food system: (1) council dynamics and structure, (2) sharing resources, expertise, and information, (3) promoting healthy food access through programs, and (4) food policy opportunities and challenges.

\section{Council Dynamics and Structure}

Council members commonly cited the egalitarian atmosphere as one of the greatest strengths of the ACFPC. One member noted, "I think people feel that their voices and contributions are really valued." This tended to be a common thought and was true for most people; "[E]veryone no matter their background, no matter their age, we are all heard." Interviewees attributed their feelings of egalitarianism to the council's structure, small size, and group dynamics. Several interviewees commented that some personalities within the council occasionally clashed, but that in general everyone "played nice" during council meetings to move the group forward. A strong commitment to the group's mission seemed to override occasional personal conflicts. Also, council members are volunteers and thus are internally motivated to participate. Although the council does not have an elected or appointed leader, several interviewees referred to another council member as an informal leader. Council members reported that equality within the council "works well" and that the group makes decisions through consensus. Most participants mentioned the importance of the AmeriCorps Vista member acting as a facilitator during council meetings to ensure they run smoothly, set meeting agendas by asking for input from all the council members via email, and to conduct the day-to-day administration of the council.

\section{Sharing Resources, Expertise, and Information}

A major activity within the council is sharing resources, expertise, ideas, and information. “That's one of our greatest strengths, that we're really good at sharing resources and ideas," explained one participant. Resources might include materials, such as gleaned produce to make gift baskets for a $5 \mathrm{~K}$ (running race) organized by a public service center. Grant writing is an example of expertise that some council members share with other members. Funding announcements were frequently mentioned as a type of information shared among council members and the organizations they work for. One interviewee described an example where sharing information, resources, and expertise between council members helped food insecure community members get connected to food access services in the community:

I might have a [diabetes] patient that is suggesting to me that they are food insecure. I can send them over to [poverty alleviation nonprofit] or I can send them to [name] in the gleaning area and be able to say, you know, 'talk to them.' I don't feel like I need to solve all of it. I have resources. And so [does] everybody in their own areas of expertise. There's a willingness there [to share].

Participants explained that sharing ideas and resources benefitted them professionally. Working together as a group strengthened participants' abilities to solve problems in their home organizations and to collectively impact the food system in Adams County. This synergistic effect of council membership could help to explain why members were committed to the council, even though it was a voluntary effort for everyone except the coordinator.

\begin{tabular}{|c|c|}
\hline Sector & $\begin{array}{c}\text { Number of Interview } \\
\text { Participants }\end{array}$ \\
\hline Academics & 2 \\
\hline Agricultural extension & 1 \\
\hline Education & 1 \\
\hline Food access organization & 1 \\
\hline Health care & 1 \\
\hline Nonprofit & 2 \\
\hline Total & 8 \\
\hline
\end{tabular}


Promoting Healthy Food Access Through Programs

The ACFPC has the important and unique function of developing, supporting, and maintaining food access-related programs that cross multiple sectors and populations in Adams County. The council also acts as a resource for county residents looking to implement food system-related changes in their community. In 2011, the council piloted the Healthy Options program. Healthy Options improves access to fresh, local produce to a diverse section of the population by providing vouchers to participants to use at Adams County Farmers' Market Association markets. Low-income families living in Adams County are eligible to participate. The Healthy Options program is supported by fundraising efforts conducted by various groups, including churches, a hospital foundation, and workplaces, and thus elevates community awareness around food insecurity in Adams County. The program increases the customer base at the farmers' market, which could increase revenue for participating farmers. Because agriculture is a major component of the economy in Adams County, increasing the sales of local produce could provide economic benefits. One participant explained, "It generates income and [farmers' market] vendors appreciate it." As the program continues to grow, the council is exploring methods to maintain its longevity, including training former participants to support new participants.

Healthy Options is a complicated program because it involves coordination among several organizations, required an organizational policy change at the markets, and seeks to effect social change. Partner organizations include the Farmers' Market Association and the South Central Community Action Program. To facilitate the program, the ACFPC encouraged the Farmers' Market Association to accept Electronic Benefit Transfers (EBT) from the Supplemental Nutrition Assistance Program (SNAP). This marked a change in the farmers' markets' organizational policy. ACFPC members also seek to effect social change through the program by reaching out to groups that are currently under-represented in the farmers' market clientele, such as Latina families, and supporting new purchasing habits. As described in one interview, "Prior to [program implementation year] those families just did not shop in the [farmers'] market at all. They didn't feel comfortable going or that it was accessible to them. Now they feel pretty comfortable going and the demographics shifted at our farmers' market." Moreover, ACFPC members who work with low-income populations in their home organizations reported referring clients and families to the Healthy Options program. The ACFPC is influencing access to healthy foods in the county through the Healthy Options program by working with partner organizations to raise funds for vouchers, conduct outreach to low-income families, and reduce barriers to using SNAP benefits at farmers' markets.

The council is also involved in gleaning efforts to recover would-be food waste and distribute it to food insecure members of the community through food pantries. A gleaning coordinator was hired by a nonprofit owing in large part to the ACFPC. The council emphasized the necessity of such a position to the county government when two community members decided they could no longer maintain a voluntary gleaning program. The county government decided to help fund the position. The gleaning coordinator is now a member of the council and works with other members to efficiently capture and distribute gleaned food. Thousands of pounds of fresh produce are moved through the county each year as a result of the network of relationships maintained by the gleaning coordinator and supported by the council. Increasing access to fresh produce is shifting expectations about the kinds of foods available to food insecure residents of Adams County. One council member said, "The food pantry clients come on a regular basis looking for those fresh fruits and vegetables." The Healthy Options program and gleaning are two examples of existing programs that the ACFPC helped to develop or maintain.

Council members reported that community members view the council as a group with the capacity to support food system initiatives in Adams County. For example, several council members described a new program that was brought to them by a community member who wanted to address hunger at his daughter's school. The community member learned about a backpack program in a nearby county where backpacks of food were sent home with food insecure children over the weekend and on holidays, when they did not have access school food. Upon learning about the ACFPC, the community member approached the council to see if they could help to launch a similar program in Adams County. Although the community member continued to be the driv- 
ing force behind the initiative, members of the council were able to advise him in the implementation of the program, helped connect him to a network of churches that provide volunteers to pack backpacks, and provided nutrition advice about what kinds of foods to provide (to avoid "sugar bombs," one participant explained). The ACFPC has played a pivotal role in developing, coordinating, or sustaining a number of food-related programs in their county.

\section{Food Policy Opportunities and Challenges}

ACFPC members are working toward policy solutions to address food system issues. Council members described their programs (such as the Healthy Options program) as "filling the gap" where food policy and systems have failed groups in the community. As one council member described, "[our programs] have had significant impact on a small number of people but I think now we're trying to think a little bigger than that so it's not small initiatives for couple hundred people but really shifting the way our food system works." Council efforts have already led to organizational policy changes, such as accepting EBT at farmers' markets and influencing food recovery policies at restaurants and grocery stores. Currently, the council is exploring approaches for affecting other food-related policies in their community. One interviewee recommended school policy as one option, although noted that school systems could be difficult to navigate owing to bureaucracy. Other members suggested reaching out to local officials and request that they join or participate with the council in some capacity. One interviewee described raising awareness about systemic issues that influence food choices for families as being an important first step for policy change:

If the goal is $x$, then how do we design policies and systems so that we can actually reach $x$ ? . . Our systems are perfectly designed in a flawed way that produces outcomes that are not beneficial for all families. And I think the first way to start the process to correct that is to be talking about the real issues.

Many council members described challenges influencing policy change. Some said that federal-level policies, such as immigration and food safety regulations, affect their local food system. This reality can feel frustrating, because the council is not currently in a position to influence federal policy. One member saw the opportunity in this challenge and said,
I think with very little training and lots and lots of passion, knowledge, study, support and collaborative work, we've been able to make some significant community changes. It would be really exciting to figure out how do we lend our voice, or engage and entice other FPCs to join us to figure out where we can make changes at the state or federal level.

Several council members noted that legislators have their own agenda, which can be both a barrier and opportunity for policy change, depending on whether food systems issues can get on that agenda.

\section{DISCUSSION}

To our knowledge, this is the first case study describing how a rural FPC in the United States can facilitate food system change in their community. During the interviews, participants explained that the egalitarian atmosphere in their council encouraged participation and group problem solving. This finding suggests the ACFPC fosters group cohesion and member empowerment, which are associated with community coalition effectiveness. ${ }^{24}$ Council members shared resources, expertise, and information with other council members to further the mission of the council; this also benefited members within their own organizations. Pooling resources and sharing information between members and members' home organizations are mechanisms FPCs and coalitions use to affect change in their communities. ${ }^{14,23,26}$ Participants described how the ACFPC helps coordinate complicated programs that aim to increase access to healthy food in their community. A study of 13 FPCs in the United States and Canada found that most councils directly worked on projects, or supported projects led by other organizations, to strengthen their local food system. ${ }^{2}$ Finally, case study participants discussed the food policy challenges and opportunities they encounter through their work with the council. Another study identified similar challenges that FPCs encounter when working to change policy, including a lack of policy change training or skills and inconsistent support from government officials. ${ }^{13}$

This case study demonstrated that membership in the ACFPC provided an opportunity to collaborate and partner with staff from a variety of organizations that may not typically work together. In a recent report about a regional FPC in rural and frontier counties in New Mexico, Winne ${ }^{29}$ stressed the importance of collaboration to address food system and 
food policy work. He explained that working on such issues in rural areas can be challenging because there are fewer people available to share the work, there are greater distances between people and places, and it takes more time for people and food to cover large distances. ${ }^{29}$ However, working in rural areas can be advantageous because, when "access to decision-makers is easier, progress can be made if and when resources are available and people work together." ${ }^{29}$ The ACFPC is working to strengthen their relationships with decision-makers in local government and continue to partner with organizations to leverage resources to increase access to healthy foods in Adams County.

\section{Limitations}

There are limitations to this study. First, this is a case study and therefore may not be generalizable to councils that are different from the ACFPC in terms of membership composition, council structure, geographic location, or other factors. Selection bias could be a limitation in that 13 council members were invited to participate in interviews and 5 chose not to. Follow-up with the council coordinator who recruited research participants indicated that those who chose to participate may have been more active in terms of working on council-specific activities that expanded beyond their duties in their home organizations compared with those who chose not to participate. Study participants could hold a more favorable view of the council than those who chose not to participate, and thus may have presented a more positive picture than would be seen if more diverse opinions were included. Not all FPCs operate as smoothly as participants described in this case study. FPCs have dissolved as a result of political changes, lack of commitment from members, and other reasons. ${ }^{10}$

\section{IMPLICATIONS FOR POLICY AND PRACTICE}

This case study provides examples of how an FPC in a rural county can influence policy and practice related to healthy food access by serving as an arena for coordination, collaboration, and partnership development. Influencing healthy food access can impact community health by reducing hunger, increas- ing economic opportunities related to local agriculture, and contributing to obesity prevention. ${ }^{30}$ Qualities of the council described in this case study can inform the organizational practices of current and future FPCs. Developing an egalitarian atmosphere in the council and encouraging the sharing of resources, information, and knowledge may benefit other FPCs. This case study also illustrates how representatives from multiple sectors in a community can coordinate food access programs in a rural setting by developing partnerships through an FPC. Moreover, the ACFPC gained credibility in its community and became a group that community members sought out to support or provide input on their own food access initiatives. In addition to supporting programs, FPC members can work toward policy changes that have a broader public health impact, ${ }^{31}$ such as influencing policies governing SNAP use at farmers' markets. Policymakers should consider partnering with or joining FPCs to identify and implement practical changes within their food system that promote access to healthy food and spur economic development related to food and agriculture. Although this case study provided a detailed picture of how an FPC functions in a rural setting, more research is needed to identify differences between rural and urban councils and to evaluate FPCs' impact on their food systems.

\section{ACKNOWLEDGMENTS}

Many thanks to the Adams County Food Policy Council for sharing your experiences for this case study. This work was conducted at the Center for Health Promotion and Disease Prevention at the University of North at Chapel Hill, a Prevention Research Center (5U48DP001944).

\section{DISCLOSURES}

One member of the research team (Camille Horton) was the former ACFPC coordinator. This individual did not conduct any interviews. Case study participants gave permission for the former coordinator to read de-identified transcripts and contribute to the development of this manuscript. Case study participants reviewed this manuscript before it was submitted for publication. 


\section{REFERENCES}

1. Roberts W. Taking it all in. Alternatives 2011;37(2).

2. Schiff R. The role of food policy councils in developing sustainable food systems. J Hunger Environ Nutr 2008;3:206-28.

3. Harper A, Shattuck A, Holt-Giménez E, et al. Food policy councils: Lessons learned. Inst Food Dev Policy 2009;1-63.

4. FPC Directory, Food Policy Networks Project. [Internet]. Johns Hopkins Bloomberg School of Public Health. [cited 2016 Jan 5]. Available from: http://www.foodpolicynetworks .org/directory

5. Glickman D, Parker L, Sim LJ, et al. Accelerating progress in obesity prevention: Solving the weight of the nation. Washington (DC): National Academies Press; 2012.

6. Mozaffarian D, Appel LJ, Van Horn L. Components of a cardioprotective diet new insights. Circulation 2011;123:2870-91.

7. Clayton ML, Frattaroli S, Palmer A, et al. The role of partnerships in U.S. Food Policy Council policy activities. PLoS One 2015;10:e0122870.

8. McClintock N, Wooten H, Brown A. Toward a food policy "First Step" in Oakland, California: A food policy council's efforts to promote urban agriculture zoning. J Agric Food Syst Community Dev 2012;2:15-42.

9. Walsh CC, Taggart M, Freedman DA, et al. The ClevelandCuyahoga County Food Policy coalition: "We have evolved." Prev Chronic Dis 2015;12:140538.

10. Coplen A, Cuneo M. Dissolved: Lessons learned from the Portland Multnomah Food Policy Council. J Agric Food Syst Community Dev 2015;Jan:91-107.

11. Blay-Palmer A. The Canadian pioneer: The genesis of urban food policy in Toronto. Int Plan Stud 2009;14:401-16.

12. Pothukuchi K, Kaufman J. Placing the food system on the urban agenda: The role of municipal institutions in food systems planning. Agric Human Values 1999;16:213-24.

13. Scherb A, Palmer A, Frattaroli S, et al. Exploring food system policy: A survey of food policy councils in the United States. J Agric Food Syst Community Dev 2012;2:3-14.

14. McCartan J, Palermo C, Booth SL, et al. The role of a food policy coalition in influencing a local food environment: an Australian case study. Public Health Nutr 201624;59:1-10.

15. Barnidge EK, Radvanyi C, Duggan K, et al. Understanding and addressing barriers to implementation of environmental and policy interventions to support physical activity and healthy eating in rural communities. J Rural Health 2013;29:97-105.

16. Walker RE, Keane CR, Burke JG. Disparities and access to healthy food in the United States: A review of food deserts literature. Health Place 2010;16:876-84.

17. Befort CA, Nazir N, Perri MG. Prevalence of obesity among adults from rural and urban areas of the United States: Findings From NHANES (2005-2008). J Rural Health 2012;28:392-7.
18. O'Connor A, Wellenius G. Rural-urban disparities in the prevalence of diabetes and coronary heart disease. Public Health 2012;126:813-20.

19. Blanck HM, Kim SA. Creating supportive nutrition environments for population health impact and health equity: An overview of the Nutrition and Obesity Policy Research and Evaluation Network's efforts. Am J Prev Med 2012;43:S85-S90.

20. U.S. Department of Agriculture (USDA). USDA economic research service: Data access and documentation downloads. 2012.

21. Dewey A, Crumbaugh A, Kato M, et al. Map the meal gap 2016: Food insecurity and child food insecurity estimates at the county level [Internet]. Feeding America. [cited 2017]. Available from: http://www.feedingamerica.org /hunger-in-america/our-research/map-the-meal-gap/2014 /PA_AllCounties_CDs_MMG_2014.pdf

22. Adams County Food Policy Council [Internet]. [cited 2016 Jan 5]. Available from: http://www.adamsfoodpolicy.org/index.html

23. Butterfoss FD, Kegler MC. The community coalition action theory. In: DiClemente RJ, Crosby RA, Kegler MC, et al., editors. Emerging theories in health promotion practice and research (2nd ed.). San Francisco: Jossey-Bass; 2009:237-76.

24. Zakocs R, Edwards E. What explains community coalition effectiveness? A review of the literature. Am J Prev Med 2006;30:351-61.

25. Granner ML, Sharpe PA. Evaluating community coalition characteristics and functioning: A summary of measurement tools. Health Educ Res 2004;19:514-32.

26. Allen NE, Javdani S, Lehrner AL, et al. "Changing the text": Modeling council capacity to produce institutionalized change. Am J Community Psychol 2012;49:317-31.

27. Ulin PR, Robinson ET, Tolley EE. Qualitative methods in public health: A field guide for applied research. San Francisco: Jossey-Bass; 2004.

28. Lieber E, Weisner TS. Dedoose. Web-based Qual Mix Comput Software. 2013.

29. Winne M. The Southwest New Mexico Food Policy Council: Thinking regionally, acting locally. Baltimore (MD): Johns Hopkins, Center for a Livable Future; 2015.

30. Centers for Disease Control and Prevention. Strategies to prevent obesity and other chronic diseases: The CDC guide to strategies to increase the consumption of fruits and vegetables. [Internet]. Atlanta: US. Department of Health and Human Services; 2011. [cited 2017 Feb 4]. Available from: http://www .cdc.gov/obesity/downloads/fandv_2011_web_tag508.pdf

31. Frieden TR. A framework for public health action: The health impact pyramid. Am J Public Health 2010;100:590-5. 